\title{
The Protection Performance of Polypyrrole Coating Doped with Different Counter Anions for the Corrosion of NiTi Alloy
}

\author{
Kai Qi, Zhenyu Chen, Guoan Zhang and Xingpeng Guo* \\ School of Chemistry and Chemical Engineering, Huazhong University of Science and Technology, Hubei Key \\ Laboratory of Materials Chemistry and Service Failure, Wuhan 430074, PR China
}

\begin{abstract}
The electrochemical corrosion behavior of NiTi alloy electrodeposited conductive polypyrrole (PPy) coatings doped with small size sulfate $\left(\mathrm{SO}_{2}{ }^{-}\right)$, medium size para-toluene sulfonate $\left(\mathrm{pTS}^{-}\right)$and large size dodecylbenzene sulfonate $\left(\mathrm{DBS}^{-}\right)$counter anions has been studied by electrochemical measurements and surface analysis. It is demonstrated that PPy coatings inhibit the corrosion of NiTi substrate in chloride solution by shifting the corrosion potential and pitting potential positively and increasing the impedance of corrosion process. The protective performance of PPy coatings for NiTi alloy is in the order: PPy/pTS $<$ PPy $/ \mathrm{SO}_{4}<\mathrm{PPy} / \mathrm{DBS}$. The protective performance of the doped PPy coatings for NiTi alloy is related to their anions exchange abilities. The worse anion exchange ability PPy coating has, the better protective performance. The increase of solution $\mathrm{pH}$ increases the corrosion rate of the coated NiTi substrate.
\end{abstract}

Keywords: NiTi alloy, polypyrrole coating, size of doping anion, corrosion.

\section{INTRODUCTION}

Nitinol, which is a nearly equiatomic NiTi alloy, is attracting more attention in medical devices and implant materials due to its distinctive thermomechanical and mechanical properties, i.e. shape memory effect, superelasticity and high damping capacity [1-4]. As a metal material for medical implant, it should be resistant to corrosion to ensure long service life and to minimize its adverse biologic effect. However, when NiTi alloy is served as implant material, the main problem is that the high concentration $\mathrm{Ni}^{2+}$ ion, which is released into the biologic environment due to the anodic dissolution of NiTi alloy, is biotoxic to human body. It has been reported that the $\mathrm{Ni}^{2+}$ ion concentration in the blood of patient would reach a level that is three times as high as that before NiTi alloy material is implanted. Furthermore, $\mathrm{Ni}^{2+}$ ion can also be redistributed to different organs via blood flow and stays there for a long time [5]. It is reported [6-9] that the good corrosion resistance and biocompatiblility of NiTi alloy are associated with the formation of a resistant titanium oxide layer on the surface, which limits the release of $\mathrm{Ni}^{2+}$ ion, but the toxicity hazard remains a subject of concern. Moreover, once the passive oxide layer is damaged, NiTi alloy can hardly repassivate and has a low resistance to localized attack. Furthermore, NiTi alloy has a relatively low pitting potential to be used for implant material in the human body [10]. Hence, it is important to find ways to mitigate the release of nickel ion and raise the breakdown potential [4, 10]. To improve the corrosion resistance of NiTi alloy, chemical passivation [11], thermal treatment [12] and surface modification techniques, such as laser welding

*Address correspondence to this author at the School of Chemistry and Chemical Engineering, Huazhong University of Science and Technology, Hubei Key Laboratory of Materials Chemistry and Service Failure, Wuhan 430074, PR China; Tel: +86-27-87543432; Fax: +86-27-87543632;

E-mail: guoxp@mail.hust.edu.cn treatment [13], laser melting surface [14] and ion implantation [15], have been used in these years.

In recent years, there has been an increasing interest in the use of conductive polymers as protective coatings against corrosion [16-20]. Polypyrrole (PPy) is particularly attractive due to its high conductivity, stability, ease of synthesis and especially very good tissue compatibility $[2,10,16]$. Moreover, PPy coating can be electrodeposited directly on the alloy surface easily [17-20]. Thus, it is expected that the application of PPy as coating material for NiTi alloy would enhance its biocompatibility and also lead to the protection against corrosion and then decrease the release of $\mathrm{Ni}^{2+}$ ion into the surrounding tissue. According to our previous research, doped anion plays an important role in the anion exchange behavior of PPy coating [21]. However, it is still not clear how the doped anion affects the protective performance of PPy coating for NiTi alloy. Although conductive PPy coating had been extensively studied on the protection for carbon steel or stainless steel [22-25], there are fewer studies on its corrosion protective performance for NiTi alloy $[2,10]$. The protective mechanism is still not well understood due to the complex interface interaction process.

In this work, PPy coatings, doped with three different sizes of counter anions, i.e. small size sulfate $\left(\mathrm{SO}_{4}{ }^{2-}\right)$, medium size para-toluene sulfonate (pTS) and large size dodecylbenzene sulfonate (DBS), were prepared on the NiTi alloy by electrodeposition. The effects of doped anions with different sizes on protective performance of PPy coatings for NiTi alloy corrosion were studied by electrochemical measurements, including potentiostatic polarization, potentiodynamic polarization and electrochemical impedance spectroscopy (EIS). The surface morphology of NiTi alloy after corrosion was also analyzed by SEM. In addition, the effect of solution $\mathrm{pH}$ on the degradation behaviour of PPy coating was also evaluated. The aim of this work is to determine the protective mechanism of PPy coatings doped 
with three different sizes of counter anions for the corrosion of NiTi alloy in the simulated biological solution.

\section{EXPERIMENTAL}

\subsection{Materials and Electrodes}

NiTi alloy, with a chemical composition (wt\%) of $56.03 \% \mathrm{Ni}$ and $43.97 \% \mathrm{Ti}$, was used in this experiment. The NiTi alloy was machined into rod with a diameter of $0.5 \mathrm{~cm}$ as working electrode (WE). Copper wire was welded to WE to ensure electrical connection for electrodeposition and electrochemical measurements. Then WE was mounted in the holder with epoxy resin leaving an exposed area of 0.196 $\mathrm{cm}^{2}$. Before each experiment, the surface of WE was ground up to 1200 grit silicon carbide paper, then degreased with acetone and rinsed with distilled water.

\subsection{Preparation of PPy Coatings}

The solutions used for electrodepositing PPy coatings were $0.1 \mathrm{M}$ pyrrole $+0.1 \mathrm{M} \mathrm{Na}_{2} \mathrm{SO}_{4}$, or $0.1 \mathrm{M}$ pyrrole $+0.1 \mathrm{M}$ NapTS, or $0.1 \mathrm{M}$ pyrrole $+0.1 \mathrm{M}$ NaDBS, respectively, which were made up from analytical grade reagents and deionized water. Pyrrole was purified by distillation before being used for solution preparation. The solutions were deaerated with nitrogen gas before electrodeposition. Prior to electrodepositing PPy coatings, the WE was activated by being immerged into the alkaline peroxide solution $(0.5 \mathrm{M} \mathrm{NaOH}+1.0 \mathrm{M}$ $\left.\mathrm{H}_{2} \mathrm{O}_{2}\right)$ at room temperature $\left(25^{\circ} \mathrm{C}\right)$ for $30 \mathrm{~min}$. The counter electrode was a large $\mathrm{Pt}$ plane and a saturated calomel electrode (SCE) was used as reference electrode. The PPy coatings were synthesized electrochemically on the NiTi electrode by galvanostatic technique with an anodic current density of $1 \mathrm{~mA} / \mathrm{cm}^{2}$ for $800 \mathrm{~s}$.

\subsection{Electrochemical Measurements}

A CS350 electrochemical workstation was used for electrochemical measurements for uncoated and PPy-coated NiTi electrodes in $0.9 \% \mathrm{NaCl}$ solution at $37^{\circ} \mathrm{C}$, which is usually used to simulate the biological environment. A threeelectrode test cell was used with a platinum plane as counter electrode and a saturated calomel electrode (SCE) as reference electrode. Uncoated and coated NiTi electrodes were employed as working electrodes. Time dependence of open circuit potential (OCP) was recorded after the electrodes being immerged into the solution. Anodic potentiodynamic scan was carried out by changing the electrode potential positively from OCP with a sweep rate of $1 \mathrm{mV} / \mathrm{s}$. Potentiostatic polarization was performed at 500 $\mathrm{mV}(\mathrm{SCE})$ and the current $v s$ time curve was recorded. The EIS measurement was performed at OCP with a $5 \mathrm{mV} \mathrm{AC}$ perturbation at the frequency from $10 \mathrm{kHz}$ to $10 \mathrm{mHz}$, with 10 points per decade. Zview ${ }^{\circledR}$ software was used to analyse the EIS data. Anodic polarization curve and EIS measurement were also performed on PPy/DBS coated NiTi electrode in the $0.9 \% \mathrm{NaCl}$ solution with various $\mathrm{pH}$ values.

\subsection{Surface Morphologies Characterization and Ion Concentration Analysis}

After electrochemical tests, electrodes were removed and rinsed with deionized water. The surface morphologies were observed by digital camera and scanning electron microscope (SEM). The concentration of $\mathrm{Ni}^{2+}$ ion releasing into the solution due to the anodic dissolution of NiTi alloy was determined by atomic absorption spectroscopy (AAS) analysis.

\section{RESULTS AND DISCUSSION}

\subsection{Electrochemical Synthesis of PPy Coatings}

Fig. (1) shows the potential vs time curves for electrochemical synthesis of PPy coatings doped with different counter anions on NiTi electrode by galvaniostatic method. It is seen that a high initial potential is observed and then decreases sharply, which is related to an overpotential for the nucleation of PPy film on the bare NiTi electrode. Then the potential reaches to a nearly stable plateau where the eletrodeposition of PPy film occurs on the electrode surface. The potential for synthesizing PPy coating in NapTS containing solution is more positive than that in NaDBS containing solution, while the synthesized potential in $\mathrm{Na}_{2} \mathrm{SO}_{4}$ containing solution is in the middle. This indicates that the synthesis of PPy coating in NapTS containing solution needs higher overpotential, i.e. higher driving force. The thickness of the PPy coating is estimated to be around $2 \mu \mathrm{m}$ from the charge consumed during the electrodeposition process by assuming a film thickness of $1 \mu \mathrm{m}$ for $0.4 \mathrm{C} / \mathrm{cm}^{2}$ charge [10]. The PPy coating with a thickness of $2 \mu \mathrm{m}$ is used in the following electrochemical tests.

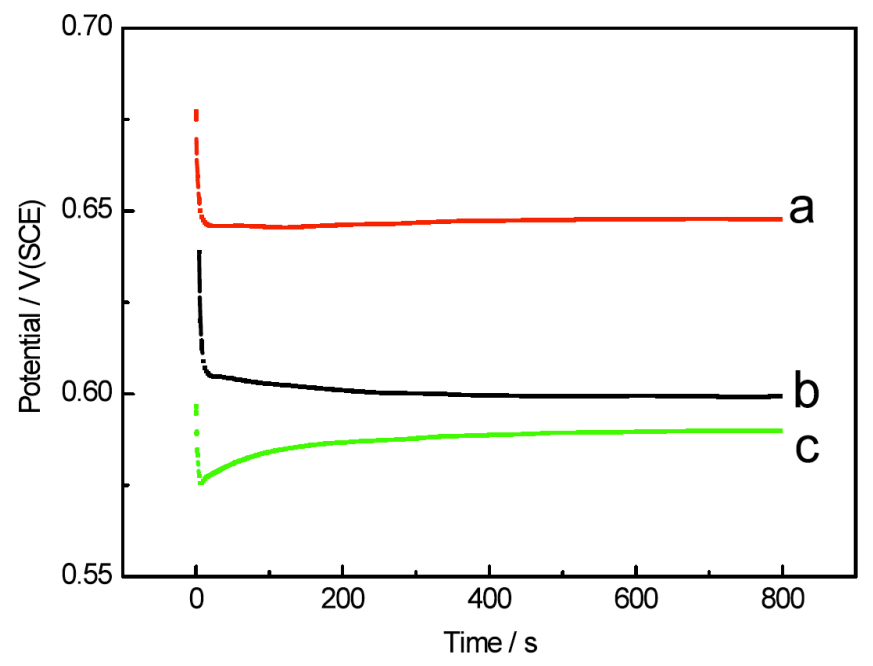

Fig. (1). Galvanostatic response obtained at $1 \mathrm{~mA} / \mathrm{cm}^{2}$ for NiTi electrode in aqueous solution of $0.1 \mathrm{M}$ pyrrole and: (a) $0.1 \mathrm{M}$ NapTS; (b) $0.1 \mathrm{M} \mathrm{Na}_{2} \mathrm{SO}_{4}$ and (c) $0.1 \mathrm{M} \mathrm{NaDBS}$.

\subsection{Open Circuit Potentials and Anodic Polarization Curves Measurements}

The open circuit potentials (OCP) vs time curves for uncoated and PPy coated NiTi electrodes in $0.9 \% \mathrm{NaCl}$ solution are shown in Fig. (2). It can be seen that the potential of the uncoated electrode shifts towards positive value at the initial stage of immersion and then reaches a steady value about $-400 \mathrm{mV}$ ( $v s \mathrm{SCE}$ ). This indicates the formation of a passive oxide film on the electrode surface. While the potentials of PPy coated electrodes shift negatively and then reach relatively steady values $(30 \mathrm{mV}$ for PPy/DBS, $50 \mathrm{mV}$ for $\mathrm{PPy} / \mathrm{SO}_{4}$ and $100 \mathrm{mV}$ for PPy/pTS, respectively), which are more positive than that of uncoated one. 


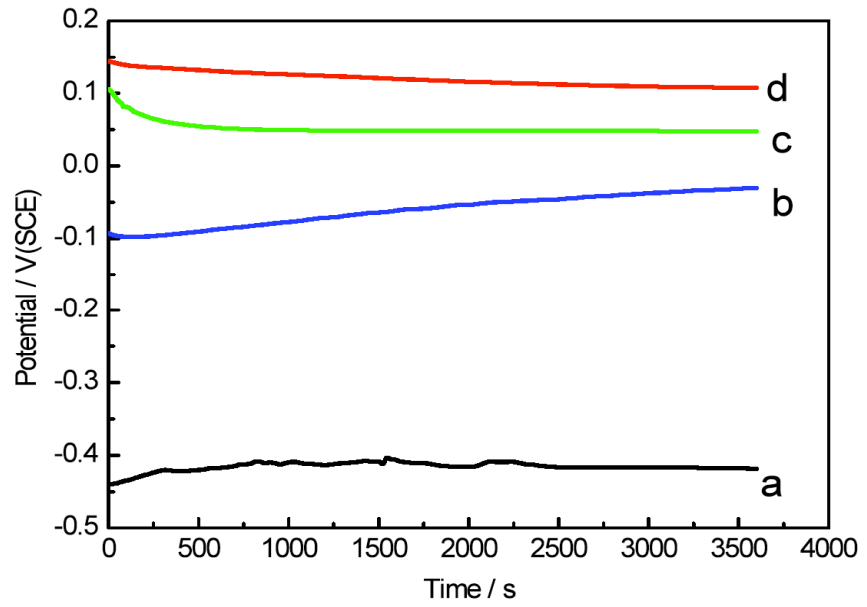

Fig. (2). Time dependence of the open circuit potential in $0.9 \%$ $\mathrm{NaCl}$ solution for: (a) uncoated NiTi electrode; (b) PPy/DBS coated NiTi electrode; (c) PPy/SO $\mathrm{SO}_{4}$ coated NiTi electrode and (d) PPy/pTS coated NiTi electrode.

Fig. (3) shows the anodic polarization curves of uncoated and PPy coated NiTi electrodes doped with three different counter anions in $0.9 \% \mathrm{NaCl}$ solution. It is seen that the anodic polarization curve of uncoated NiTi electrode is characterized by a passive region in the potential range from $-400 \mathrm{mV}$ to $300 \mathrm{mV}$ (SCE). The polarization current density starts to increase dramatically above approximate $300 \mathrm{mV}$ (SCE), indicating the breakdown of passive film and the initiation and propagation of pits. This measured breakdown potential is in accordance with the values reported previously [10]. Obvious passive regions are also observed in PPy coated NiTi electrodes doped with three different counter anions. The "apparent passive" regions shift positively comparing to that of uncoated electrode. The pitting potentials of $\mathrm{PPy} / \mathrm{pTS}, \mathrm{PPy} / \mathrm{SO}_{4}$ and $\mathrm{PPy} / \mathrm{DBS}$ coated electrodes are about $460 \mathrm{mV}, 590 \mathrm{mV}$ and $690 \mathrm{mV}$ (SCE), respectively, which are more positive than that of uncoated electrode. The "apparent passive" current density of PPy/DBS coated electrode is obvious lower than those of $\mathrm{PPy} / \mathrm{pTS}$ and $\mathrm{PPy} / \mathrm{SO}_{4}$ coated electrodes, which indicates that PPy/DBS coating has better protective performance for NiTi substrate. In addition, the "apparent passive" current densities of PPy/pTS and $\mathrm{PPy} / \mathrm{SO}_{4}$ coated electrodes are higher than that of uncoated electrode, but it does not mean higher anodic dissolution rates of NiTi electrodes under $\mathrm{PPy} / \mathrm{pTS}$ and $\mathrm{PPy} / \mathrm{SO}_{4}$ coatings. It is an overestimation of anodic dissolution current density for PPy coated electrodes due to the fact that part of the measured current density results from the oxidation of polymer coating. However, these anodic polarization curves are still useful for the comparison of the relative performances of various types of polymer coatings being tested under the same condition [2628 ]. Actually, the corrosion rates of uncoated and PPy coated electrodes were also determined by $\mathrm{Ni}^{2+}$ ion concentration in solution after exposure to $0.9 \% \mathrm{NaCl}$ solution for 7 days. The quantity of $\mathrm{Ni}^{2+}$ ion in solution for the uncoated electrode is $5.7 \mu \mathrm{g} / \mathrm{cm}^{2}$ while the concentrations of $\mathrm{Ni}^{2+}$ ions in solutions for all the PPy-coated electrodes are so low that they can not be detected by AAS. Thus, the anodic dissolution of NiTi substrate is inhibited significantly by PPy coatings, i.e. the low corrosion rates of PPy coated electrodes.

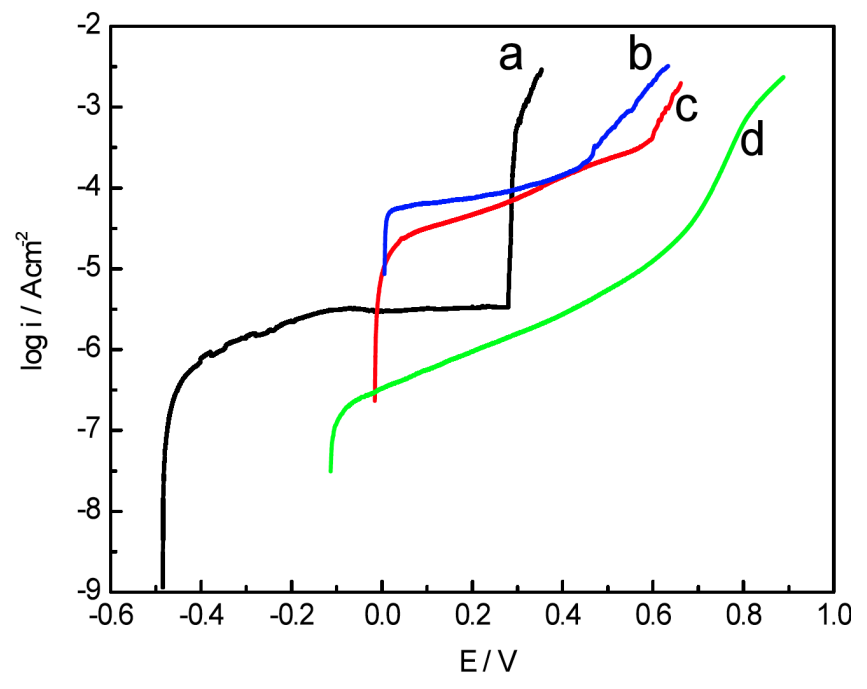

Fig. (3). Anodic polarization curves in $0.9 \% \mathrm{NaCl}$ solution for: (a) uncoated NiTi electrode; (b) PPy/pTS coated NiTi electrode; (c) $\mathrm{PPy} / \mathrm{SO}_{4}$ coated NiTi electrode and (d) $\mathrm{PPy} / \mathrm{DBS}$ coated NiTi electrode.

\subsection{Electrochemical Corrosion Behavior Under Anodic Polarization}

In order to further study the performances of PPy coatings doped with different counter anions, potentiostatic polarization at $500 \mathrm{mV}$ (SCE) is applied to the uncoated and coated electrodes for $1800 \mathrm{~s}$ after immersion in the solution for $1 \mathrm{~h}$. Fig. (4) shows the polarization current densities $v s$ time curves of different electrodes. It can be seen that the current density of uncoated electrode increases immediately after applying anodic potential, which indicates the occurrence of pitting corrosion. For PPy/pTS and $\mathrm{PPy} / \mathrm{SO}_{4}$ coated electrodes, there are obvious incubation periods, i.e. 550 s and 800 s respectively, for pitting corrosion. Furthermore, obvious current oscillations, which are the typical sign of pitting corrosion, are observed after pitting corrosion incubation periods. However, no increasing trend of current density of PPy/DBS coated electrode is observed in the whole period of $1800 \mathrm{~s}$, indicating that PPy/DBS coated electrode is still in passive state and no pitting corrosion occurs.

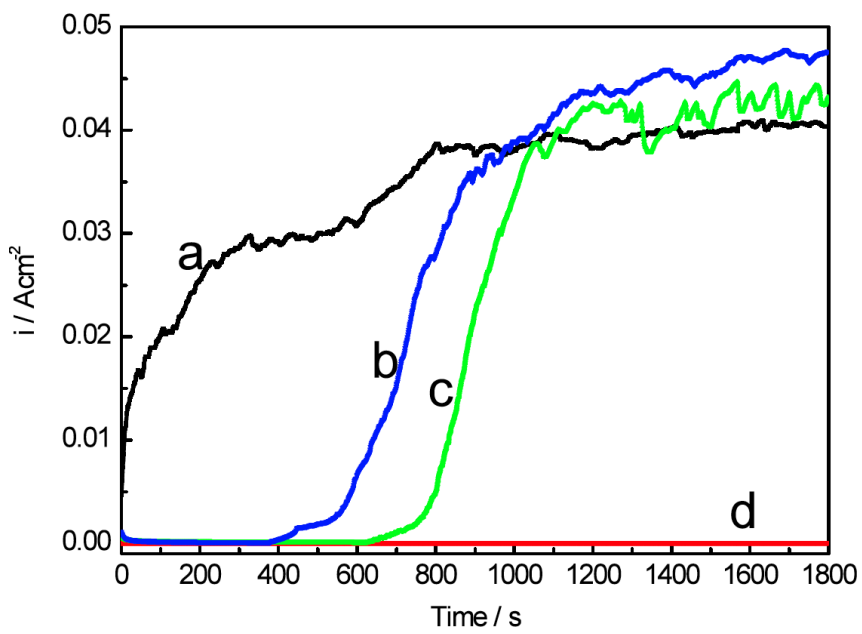

Fig. (4). Potentiostatic response obtained at $500 \mathrm{mV}$ (SCE) in $0.9 \%$ $\mathrm{NaCl}$ solution: (a) uncoated NiTi electrode; (b) PPy/pTS coated NiTi electrode; (c) $\mathrm{PPy} / \mathrm{SO}_{4}$ coated NiTi electrode and (d) PPy/DBS coated NiTi electrode. 
The concentrations of $\mathrm{Ni}^{2+}$ ion after potentiostatic polarization at $500 \mathrm{mV}(\mathrm{SCE})$ in $0.9 \% \mathrm{NaCl}$ solution are also analyzed by AAS. For the uncoated electrode, the concentration of $\mathrm{Ni}^{2+}$ ion in solution is $1.363 \mathrm{mg} / \mathrm{cm}^{2}$ while the quantity of $\mathrm{Ni}^{2+}$ ions releasing from PPy/pTS and $\mathrm{PPy} / \mathrm{SO}_{4}$ coated electrodes are 1.301 and $0.773 \mathrm{mg} / \mathrm{cm}^{2}$, respectively. The release of $\mathrm{Ni}^{2+}$ ion from PPy/DBS coated electrode is $0.078 \mathrm{mg} / \mathrm{cm}^{2}$, which is much lower than those of others electrodes. Fig. (5) shows the images of surface morphologies of the uncoated and PPy coated electrodes after potentiostatic polarization and PPy coatings being removed, respectively. It can be observed clearly that the NiTi electrode with PPy/DBS coating does not suffer from pitting corrosion after potentiostatic polarization, while the others electrodes undergo different levels of pitting corrosion after the same experimental condition. These obtained results confirm that the PPy coating doped with $\mathrm{DBS}^{-}$offers more effective protection to localized corrosion in aggressive media for NiTi substrate than the one doped with $\mathrm{SO}_{4}{ }^{2-}$ or pTS .

In the condition of potentiostatic polarization at $500 \mathrm{mV}$ (SCE), the PPy film will present anion exchange behavior, mainly corrosive $\mathrm{Cl}^{-}$exchange in the $0.9 \% \mathrm{NaCl}$ solution. Thus, the corrosion protection for the NiTi substrate may significantly relate to the anion exchange behavior of PPy film, i.e. the ability of inhibiting the migration of corrosive $\mathrm{Cl}^{-}$to the substrate. According to our previous research, when the counter ions are small $\left(\mathrm{SO}_{4}{ }^{2-}\right)$ and medium $\left(\mathrm{pTS}^{-}\right)$ sizes, the anion exchange behavior of PPy/A (A: $\mathrm{SO}_{4}{ }^{2-}, \mathrm{pTS}^{-}$, $\left.\mathrm{DBS}^{-}\right)$is not directly related to the size of the anion dopant, and may be determined mainly by PPy chain structure which would be affected by the dopant [21]. Moreover, the PPy/pTS film exhibits better $\mathrm{Cl}^{-}$exchange behavior than $\mathrm{PPy} / \mathrm{SO}_{4}$, i.e. worse corrosion inhibition ability. When PPy is doped with large anions, the anion size has a dominant influence on $\mathrm{Cl}^{-}$exchange ability [21]. Thus, PPy/DBS

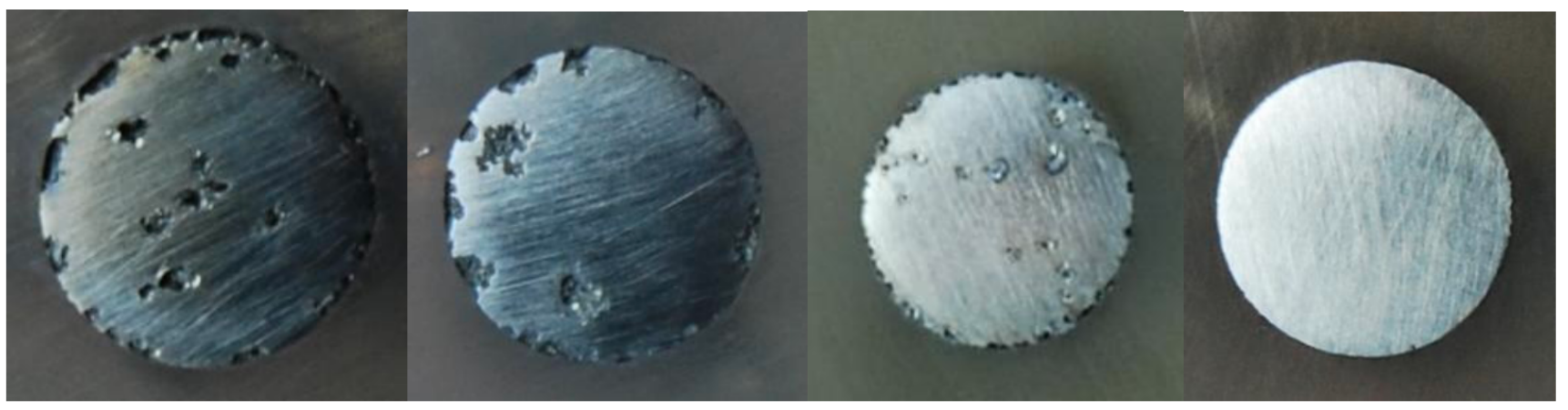

(a)

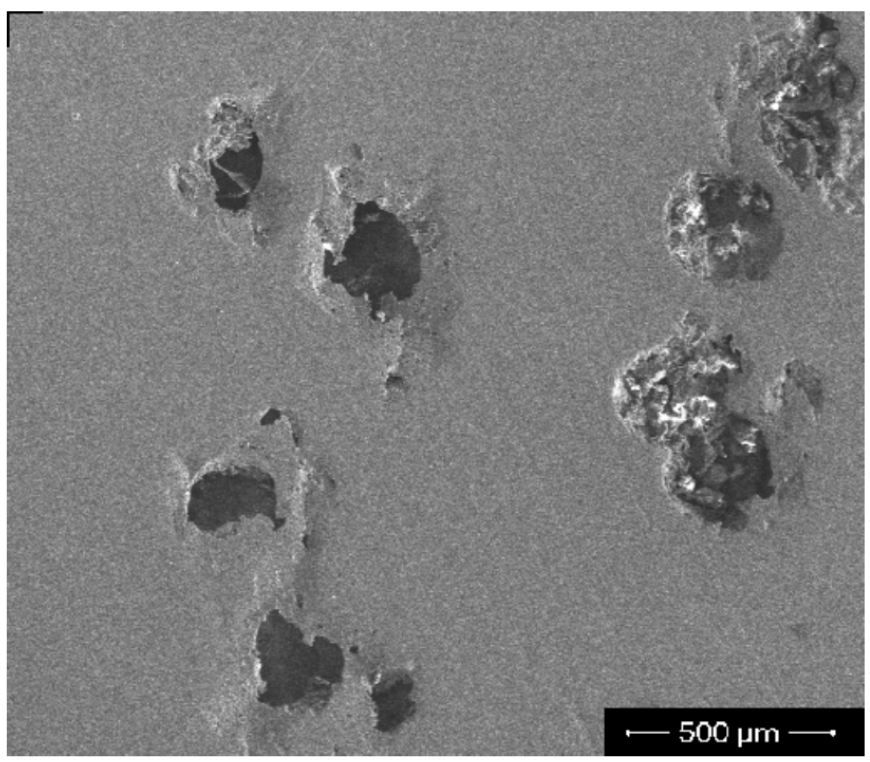

(c)

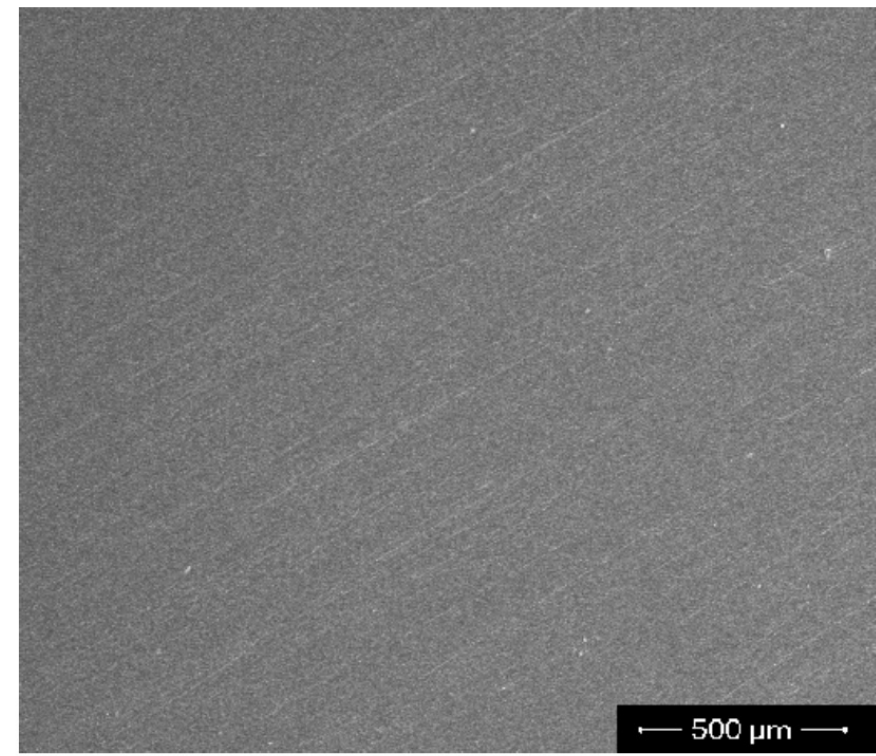

Fig. (5). The images of surface morphologies of the uncoated NiTi and PPy coated NiTi electrodes after potentiostatic polarization in $0.9 \%$ $\mathrm{NaCl}$ solution and removal of PPy coating: (a) uncoated NiTi electrode; (b) PPy/pTS coated NiTi electrode; (c)and(e) PPy/SO 4 coaed NiTi electrode; (d)and(f) PPy/DBS coated NiTi electrode. 
(doped with the large $\mathrm{DBS}^{-}$) coating repels anions due to its poor $\mathrm{Cl}^{-}$exchange ability or cation permselectivity, and then effectively resists to corrosion.

\subsection{Electrochemical Corrosion Behavior After Immersion for Different Times}

Fig. (6) shows the corrosion potential versus time curves of uncoated electrode and three types of PPy coated electrodes in $0.9 \% \mathrm{NaCl}$ solution. The corrosion potential of the bare NiTi electrode increases to around $-260 \mathrm{mV}$ during $144 \mathrm{~h}$ immersion (not shown in the figure). By comparison, the corrosion potentials of all the coated electrodes maintain between 80 and $100 \mathrm{mV}$ after $240 \mathrm{~h}$ immersion, which are much higher than that of the substrate, indicating the excellent protection of the coatings. The noble corrosion potentials of PPy-coated NiTi electrodes are probably attributed to the formation of passive film on NiTi alloy at the bottom of the PPy pores. The corrosion potential of $\mathrm{PPy} / \mathrm{pTS}$ coated NiTi electrode tends to decrease with time during the $240 \mathrm{~h}$ immersion, which is probably related to the increasing amount of solution held within the polymer coating and the increasing mobility of corrosive species and the permeability of coating. Furthermore, the reduction of the PPy film caused by the "auto-undoping" progress of PPy may also result in the decrease of corrosion potential, as observed elsewhere [29]. However, the corrosion potentials of the PPy/SO $\mathrm{SO}_{4}$ or PPy/DBS coated electrodes increase with time, which is probably ascribed to the passivation of the substrate with the catalytic effect of the PPy coating. Additionally, the slow increase in corrosion potentials of the coated NiTi electrodes may also be related to the oxidation of PPy in the presence of nucleophile, such as $\mathrm{H}_{2} \mathrm{O}$ [22]. The undoping oxidation process of PPy coating may lead to the degradation of the coating, but this process is very slow at open circuit potential, and thus no obvious degradation can be observed during whole test.

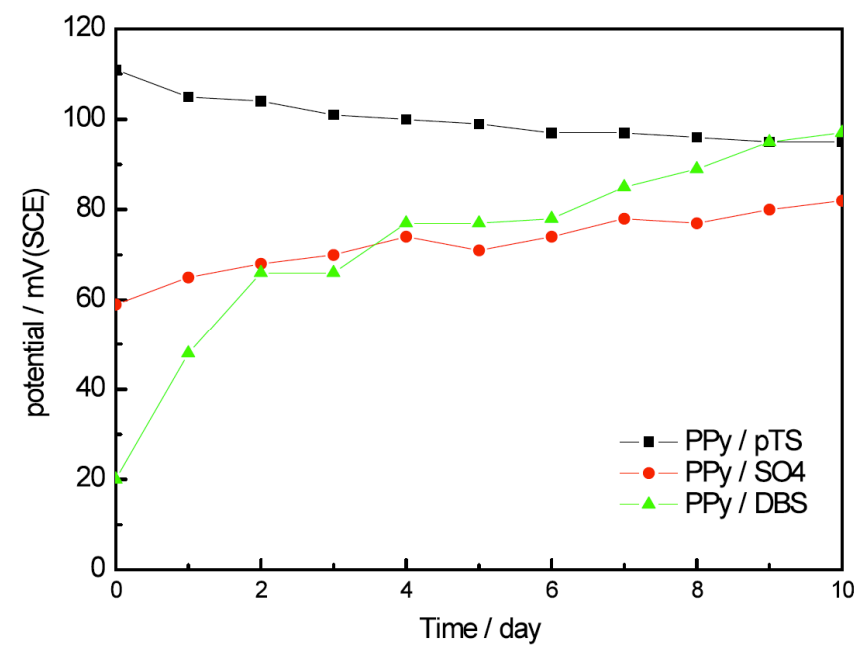

Fig. (6). Corrosion potential vs time curves of the PPy coated electrodes in $0.9 \% \mathrm{NaCl}$ solution at $37{ }^{\circ} \mathrm{C}$.

Figs. (7) shows the typical Nyquist plots of three types of PPy coated electrodes after immersion in $0.9 \% \mathrm{NaCl}$ for various times. To analyze the impedance spectra, equivalent circuits (ECs) given in Fig. (8) were used. The values of impedance parameters, which are obtained by fitting the impedance data with Zview software using an equivalent circuit, are listed in Table $\mathbf{1}$.
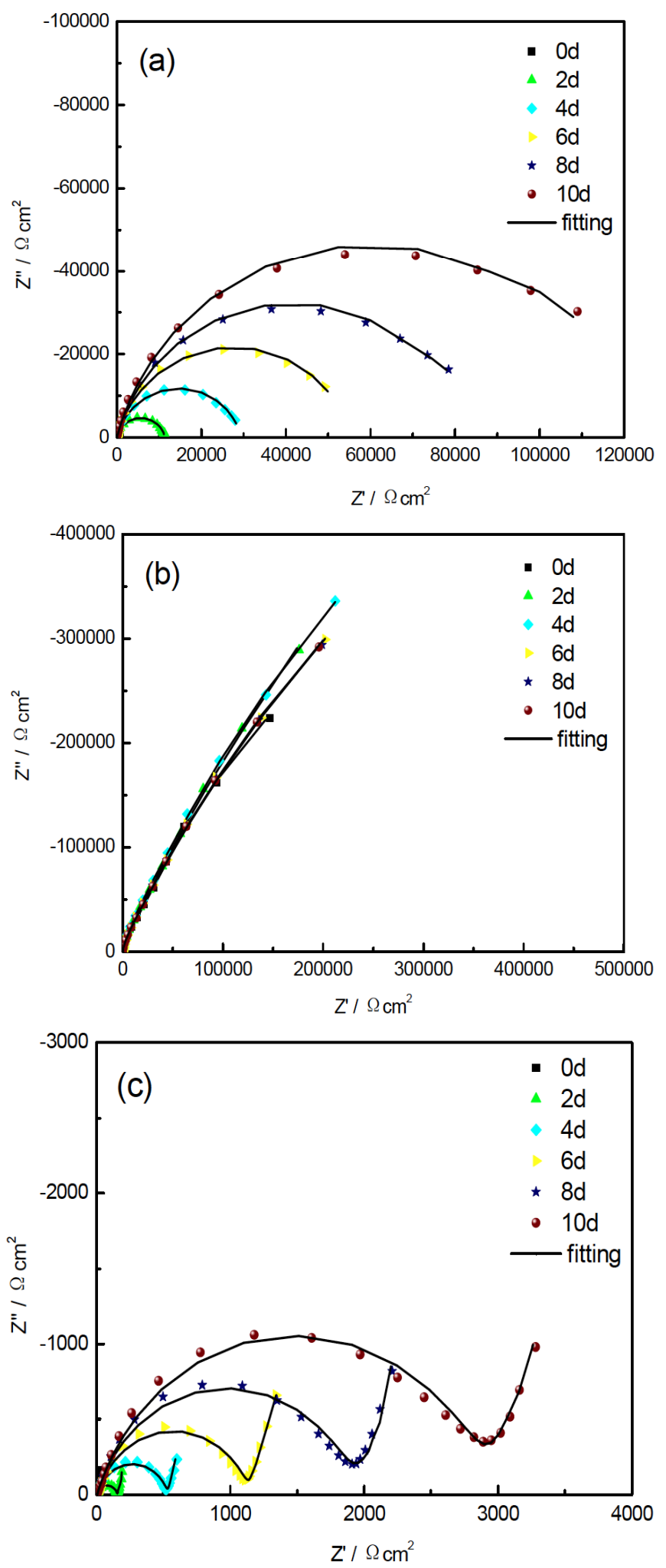

Fig. (7). Nyquist plots of PPy coated NiTi electrodes after immersion in $0.9 \% \mathrm{NaCl}$ solution at $37^{\circ} \mathrm{C}$ for various times (symbol: experimental data, line: fitted data): (a) $\mathrm{PPy} / \mathrm{SO}_{4}$ coated NiTi electrode; (b) PPy/DBS coated NiTi electrode; (c) PPy/pTS coated NiTi electrode. 

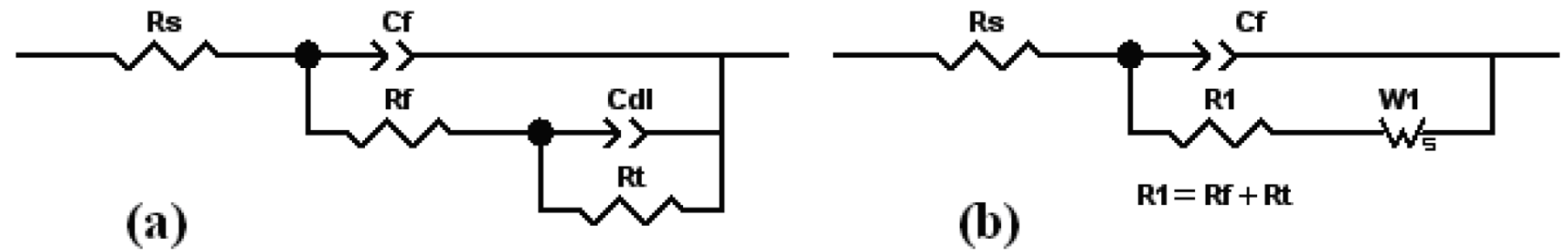

Fig. (8). Equivalent circuits representing impedance spectra of (a) $\mathrm{PPy} / \mathrm{SO}_{4}$ or PPy/DBS coated NiTi electrodes and (b) PPy/pTS coated NiTi electrode in $0.9 \% \mathrm{NaCl}$ solution at $37^{\circ} \mathrm{C}$.

For $\mathrm{PPy} / \mathrm{DBS}$ and $\mathrm{PPy} / \mathrm{SO}_{4}$ coated electrodes, it seems that there is only one capacitive semicircle, i.e. one time constant in the Nyquist plot. However, the Bode plot shows that there are two time constants and a dual time constants EC (Fig. 8a) is necessary for curve fitting. This indicates that the Nyquist plot is actually two overlapping capacitive semicircles due to their close time constants. This EC is the most frequent circuit model which is used to describe corrosion mechanism of metal/polymer electrode [29]. The high frequency section reflects the response from the PPy coating, where $C_{f}$ represents the film capacitance and $R_{f}$ is sum of the electronic resistance $\mathrm{R}_{\mathrm{e}}$ (describing the movement of the electrons in the PPy chains) and the ionic resistance $R_{i}$ of electrolyte within the pores of PPy. The low frequency part is related to the response from the electrochemical reaction occurring at the coating/substrate interface, where $\mathrm{C}_{\mathrm{dl}}$ and $\mathrm{R}_{\mathrm{t}}$ are the double-layer capacitance and the charge transfer resistance along the coating/substrate interface, respectively. A non-ideal capacitive response of the corrosion system is taken account by using a constant phase element (CPE) instead of a pure capacitance for more accurate results in the fitting procedures. The impedance of $\mathrm{CPE}$ is written as $\mathrm{Z}_{\mathrm{CPE}}=Y_{0}^{-1}(j \omega)^{-\mathrm{n}}$, where $Y_{0}$ is the admittance of CPE and $n(n=0 \sim 1)$ is an exponential term $[29,30]$.

It can be seen from Table 1 that the parameter $R_{f}$ of $\mathrm{PPy} / \mathrm{SO}_{4}$ coated electrode decreases significantly from 388.1 to $6.814 \Omega \mathrm{cm}^{2}$ after the $1 \mathrm{st}$ day immersion, which is related to the inward penetration of aqueous medium. Then the value of $R_{f}$ increases with further immersion, which is ascribed to the reduction of PPy film with the "autoundoping" progress. The increase of $R_{t}$ is attributed to the formation of the passive oxide layer, which is due to further oxidation under catalyzing effect of PPy coating. It is seen that the capacitive loop of $\mathrm{PPy} / \mathrm{SO}_{4}$ coated electrode expands with the immersion time during the whole test stage (see Fig. 7a).

The impedance features of PPy/DBS coated electrode do not change evidently with time during 10 days immersion except that the total impedance tends to increase at initial stage, and then becomes steady at later stage. The increase of $\mathrm{R}_{\mathrm{f}}$ is related to the reduction of PPy coating during immersion, which increases the movement resistance of the electrons $\left(R_{e}\right)$. Then the value of $R_{f}$ decreases to a relatively low steady value. The value of $R_{t}$ increases to a relatively steady value, which is related to the anodic protection of PPy coating, i.e. PPy coating promotes the passivation of NiTi subtrate by catalyzing effect. Furthermore, the PPy/DBS coating acts as an effective barrier to the migration of corrosive species to the substrate. It is seen that both $R_{f}$ and $\mathrm{R}_{\mathrm{t}}$ of PPy/DBS coated electrode are much higher than those of $\mathrm{PPy} / \mathrm{SO}_{4}$ coated electrode, which is ascribed to the poor $\mathrm{Cl}^{-}$exchange ability of PPy/DBS coating and the effective inhibition of the inward penetration of aqueous medium.

For PPy/pTS coating, however, the Nyquist plots are characterized by depressed semicircle at high frequencies followed by a linear part extending to lower frequencies region (see Fig. 7c). A new equivalent circuit model

Table 1. Fitting Results of Impedance Spectra for PPy-Coated NiTi Electrodes After Exposure to $0.9 \%$ NaCl Solution at $37{ }^{\circ} \mathrm{C}$ for Various Times

\begin{tabular}{|c|c|c|c|c|c|}
\hline Time (Day) & $\begin{array}{c}\text { PPy/pTS } \\
\text { R1 }\left(\mathrm{Rcm}^{2}\right)\end{array}$ & $\begin{array}{c}\mathrm{PPy} / \mathrm{SO}_{4} \\
\operatorname{Rf}\left(\mathbf{\Omega c m}^{2}\right)\end{array}$ & $\begin{array}{c}\mathrm{PPy} / \mathrm{SO}_{4} \\
\operatorname{Rt}\left(\mathbf{\Omega c m}^{2}\right)\end{array}$ & $\begin{array}{c}\text { PPy/DBS } \\
\operatorname{Rf}\left(\Omega \mathrm{cm}^{2}\right)\end{array}$ & $\begin{array}{c}\text { PPy/DBS } \\
\operatorname{Rt}\left(\Omega \mathrm{cm}^{2}\right)\end{array}$ \\
\hline $0(1 \mathrm{~h})$ & 13.10 & 388.1 & 1366 & 67643 & $1.028 \mathrm{E} 6$ \\
\hline 1 & 47.85 & 6.814 & 4831 & 90769 & $1.302 \mathrm{E} 6$ \\
\hline 2 & 148.6 & 17.23 & $1.126 \mathrm{E} 4$ & 95430 & $2.9719 \mathrm{E} 6$ \\
\hline 3 & 304.3 & 49.69 & $1.962 \mathrm{E} 4$ & 97080 & $2.0348 \mathrm{E} 6$ \\
\hline 4 & 526.5 & 307.9 & $2.919 \mathrm{E} 4$ & 104450 & $2.1936 \mathrm{E} 6$ \\
\hline 5 & 811.3 & 969.3 & $4.237 \mathrm{E} 4$ & 103760 & $2.0135 \mathrm{E} 6$ \\
\hline 6 & 1138 & 1792 & $5.502 \mathrm{E} 4$ & 86100 & $2.0944 \mathrm{E} 6$ \\
\hline 7 & 1516 & 2025 & $6.803 \mathrm{E} 4$ & 89896 & $2.0821 \mathrm{E} 6$ \\
\hline 8 & 1920 & 2609 & $8.247 \mathrm{E} 4$ & 79056 & $2.1509 \mathrm{E} 6$ \\
\hline 9 & 2357 & 3320 & $9.884 \mathrm{E} 4$ & 76799 & $2.0974 \mathrm{E} 6$ \\
\hline 10 & 2929 & 4479 & $1.128 \mathrm{E} 5$ & 75399 & $2.0736 \mathrm{E} 6$ \\
\hline
\end{tabular}


presented in Fig. (8b) is used for fitting the experimental data, which is also a common model being used to interpret a metal/polymer corrosion system [30]. The value of capacitive semicircle's diameter is equal to $R_{1}$, which is a sum of the coating and coating/substrate interface resistances. $C_{1}$ is the sum of coating and double-layer capacitances. The low frequency line is related to the doping/undoping processes controlled by the diffusion of species in the PPy coating and $\mathrm{W}_{\mathrm{s}}$ represents the diffusion impedance. Table 1 also indicates that $R_{1}$ increases with the progress of corrosion. This is ascribed to the increase of PPy coating resistance $\left(R_{f}\right)$ due to reduction of PPy and the increase of coating/substrate interface resistance $\left(R_{t}\right)$ due to further passivation of NiTi electrode under the catalyzing effect of PPy.

It is also seen from Table $\mathbf{1}$ that the order of total impedances of coated electrodes after $1 \mathrm{~h}$ immersion is: $\mathrm{PPy} / \mathrm{pTS}<\mathrm{PPy} / \mathrm{SO}_{4}<\mathrm{PPy} / \mathrm{DBS}$, which is consistent with the results of anodic polarization and potentiostatic polarization. According to the fitting results listed in the Table 1, it is reasonable to deduce that the PPy coating acts as a barrier against the corrosive species reaching the surface of the NiTi electrodes at open circuit potential, regardless of the type of the counter ions, and still offers effective protection for the substrate even after 10 days immersion. In addition, the inhibition effect on corrosion of NiTi subtracte is also attributed to the anodic protection of the PPy coating, i.e. PPy coating promotes the passivation of NiTi subtrate by catalyzing effect. Fig. (9) schematically illustrates this process. At the initial stage, the NiTi substrate under the pores in PPy coating dissolves at a potential range corresponding to the active domain. The electron produced by anodic dissolution of NiTi substrate has catalytic effect on the reduction reaction of PPy coating. The cathodic process is enhanced by the reduction of PPy coating, which in turn promotes the passivation of NiTi substrate, just as the oxidant. When the electrode potential shifts sufficiently positive by coupling of the PPy coating, then the NiTi electrode under PPy pores becomes passive.

$$
\begin{aligned}
& \mathrm{Ni}+2 \mathrm{H}_{2} \mathrm{O} \rightarrow \mathrm{Ni}(\mathrm{OH})_{2}+2 \mathrm{H}^{+}+2 \mathrm{e}^{-} \\
& \mathrm{Ti}+4 \mathrm{H}_{2} \mathrm{O} \rightarrow \mathrm{Ti}(\mathrm{OH})_{4}+4 \mathrm{H}^{+}+4 \mathrm{e}^{-} \\
& \mathrm{Ni}(\mathrm{OH})_{2} \rightarrow \mathrm{NiO}+\mathrm{H}_{2} \mathrm{O} \\
& \mathrm{Ti}(\mathrm{OH})_{4} \rightarrow \mathrm{TiO}_{2}+2 \mathrm{H}_{2} \mathrm{O}
\end{aligned}
$$

The reduction of PPy would proceed by consumption of electrons produced by reactions (1) and (2):

$\left[\mathrm{PPy}^{\mathrm{y}+} \mathrm{A}_{\mathrm{y}}^{-}\right]_{\mathrm{n}}+\mathrm{nye}^{-} \rightarrow\left[\mathrm{PPy}^{0}\right]_{\mathrm{n}}+\mathrm{ny} \mathrm{A}^{-}$

The reduction of dissolved oxygen balances partly the electrons:

$\mathrm{O}_{2}+2 \mathrm{H}_{2} \mathrm{O}+4 \mathrm{e}^{-} \rightarrow 4 \mathrm{OH}^{-}$

\subsection{Effect of the $\mathrm{pH}$ of Corrosive Medium}

The $\mathrm{pH}$ of the physiological medium is an important aspect to influence the performance of PPy coated electrodes. The $\mathrm{pH}$ of normal blood and interstitial fluid is around 7.4. However, the $\mathrm{pH}$ would decrease to about 5.2 in the hard tissue due to implantation, and then recover to 7.4 within 2 weeks [1]. With the purpose of evaluating the effect of $\mathrm{pH}$ on the corrosion behaviour of PPy-coated NiTi alloy, polarization curves and EIS were performed in $0.9 \% \mathrm{NaCl}$ solutions with the $\mathrm{pH}$ of $3,5.7,7.4$ and 10 at $37^{\circ} \mathrm{C}$. These different $\mathrm{pH}$ values were used to simulate an inflammatory or allergenic reaction in the human body.
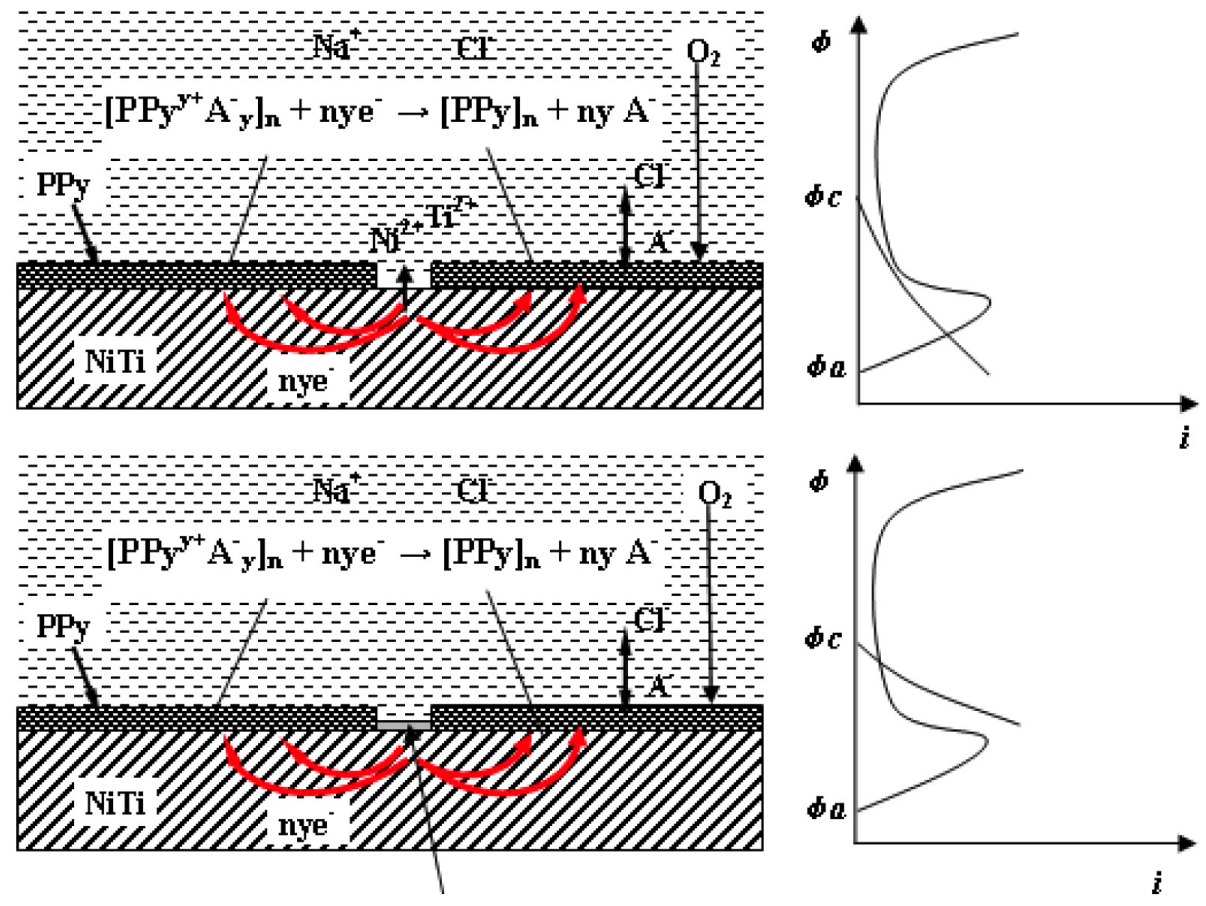

Passive film

$\left(\mathrm{NiO}, \mathrm{TiO}_{2}, \mathrm{Ni}(\mathrm{OH})_{2}, \mathrm{Ti}(\mathrm{OH})_{4}\right)$

Fig. (9). Schematic of protection effect of PPy film by promoting the passivation of NiTi subtrate.. 
Fig. (10) shows the anodic polarization curves of PPy/DBS coated NiTi electrode in $0.9 \% \mathrm{NaCl}$ solutions with various $\mathrm{pH}$ values. It is seen that the anodic current densities increase with increase of $\mathrm{pH}$. In addition, Fig. (11) shows that both the Rt and Rf, which are obtained by fitting of EIS data, decrease as the $\mathrm{pH}$ of solutions increase. Both the polarization curves and EIS indicate that the corrosion rate increases with increase of $\mathrm{pH}$. This may be attributed to the effect of $\mathrm{pH}$ on the progress of protonation/deprotonation of PPy. It is obvious that a significant decrease in breakdown potential of PPy/DBS coated NiTi electeode is observed when the corrosive medium is alkaline, while in the neutral or acidic medium, the PPy/DBS coating is more protective for the substrate. It is proved that in acidic solution, protonacid doping occurs while in alkaline solution, PPy would be deprotonated and confronted overoxidization. Therefore, the chains of PPy become vulnerable, resulting in the escape of the large counter anions $\mathrm{DBS}^{-}$.

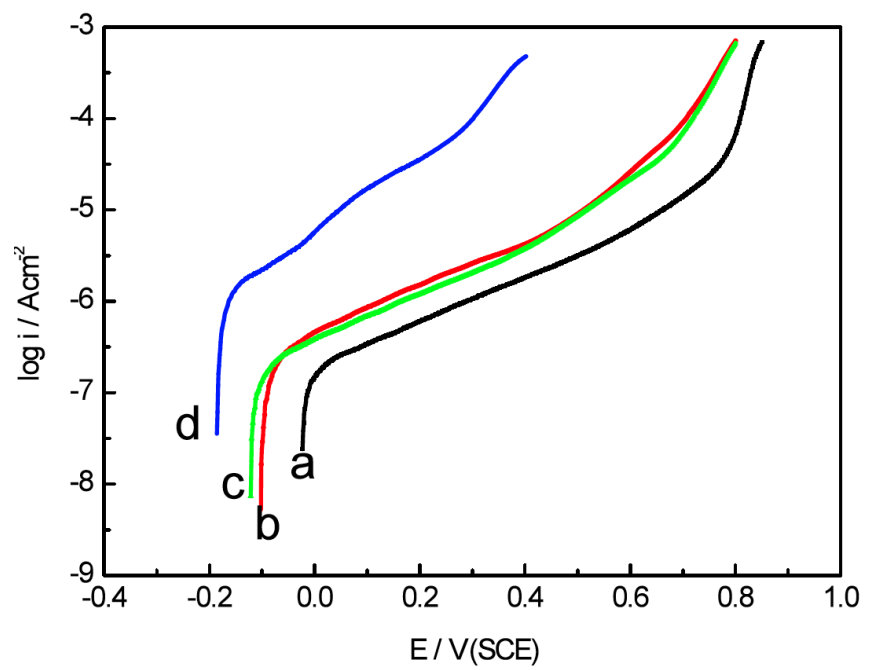

Fig. (10). Anodic polarization curves obtained for PPy/DBS coated NiTi electrode in $0.9 \% \mathrm{NaCl}$ solution with different $\mathrm{pH}$ values at 37 ${ }^{\circ} \mathrm{C}$ after $1 \mathrm{~h}$ immersion: (a) $\mathrm{pH}=3$; (b) $\mathrm{pH}=5.7$; (c) $\mathrm{pH}=7.4$ and (d) $\mathrm{pH}=10$.

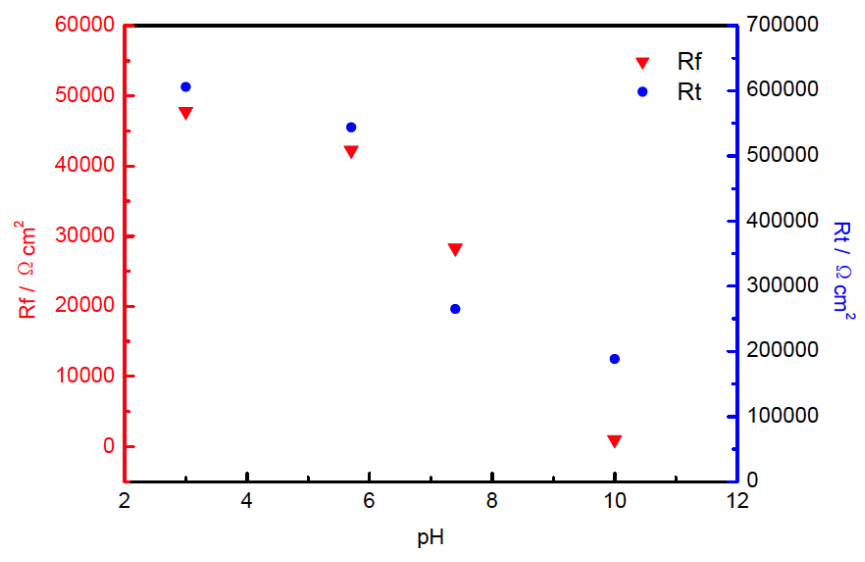

Fig. (11). Fitted EIS parameters of PPy/DBS coated NiTi alloy in $0.9 \% \mathrm{NaCl}$ solution with different $\mathrm{pH}$ values at $37^{\circ} \mathrm{C}$ after $1 \mathrm{~h}$ immersion.

\section{CONCLUSIONS}

The PPy coating is able to mitigate the corrosion of the NiTi substrate in chloride solution by shifting corrosion potentials positively and increasing the impedance of corrosion process. The pitting potentials of PPy coated electrodes also shift positively, indicating that PPy coating has the ability to protect NiTi alloy against localized corrosion. This is attributed to the effective barrier of the polymer layer and the stabilization of the passive oxide film through interaction between PPy and the underlying NiTi alloy.

The protective performance of PPy coatings for NiTi alloy in chloride solution is in the order: $\mathrm{PPy} / \mathrm{pTS}<\mathrm{PPy} / \mathrm{SO}_{4}$ $<$ PPy/DBS. The corrosion protection for the NiTi substrate is significantly related to the anion exchange behavior of PPy coating, i.e. the ability of inhibiting the migration of corrosive $\mathrm{Cl}^{-}$to the substrate. The excellent protective performance of PPy/DBS coating for NiTi alloy is due to the fact that PPy/DBS coating, doped with the large DBS, repels $\mathrm{Cl}^{-}$due to its poor anions exchange ability or cation permselectivity, while PPy/pTS coating exhibits better $\mathrm{Cl}^{-}$ exchange behavior and then the less protection for NiTi substrate.

Significant degradation in the protective performance of PPy coating is detected with increase of the $\mathrm{pH}$ of corrosive medium, which is attributted to the deprotonation and overoxidization of PPy in the alkaline medium.

\section{ACKNOWLEDGEMENTS}

The authors wish to acknowledge the financial support of the National Natural Science Foundation of China (No. 50871044).

\section{REFERENCES}

[1] Figueira N, Silva TM, Carmezim MJ, Fernandes JCS. Corrosion Behavior of NiTi Alloy. Electrochimica Acta 2009; 54: 921-6. Torabi M, Sadrnezhaad SK. Corrosion behavior of polypyrrole/hydroxyapatite nanocomposite thin films electropolymerized on NiTi substrates in simulated body fluid. Materials Corr 2010; 61: No9999.

[3] Zhang D, Zeng W, Zi Z, Chu PK. Corrosion resistance of TiN coated biomedical nitinol under deformation. Mat Sci Eng: C 2009; 29: 1599-603.

[4] Denton M, Earthman JC. Corrosion evaluation of wear tested nitinol wire. Mat Sci Eng: C 2005; 25: 276-81.

[5] Shabalovskaya SA, Rondelli GC, Undisz AL, Anderegg JW, Burleigh TD, Rettenmayr ME. The electrochemical characteristics of native Nitinol surfaces. Biomaterials 2009; 30: 3662-71.

[6] Duerig T, Pelton A, Stöckel D. An overview of nitinol medical applications. Mat Sci Eng: A 1999; 273-275: 149-60.

[7] Wever DJ, Veldhuizen AG, Sanders MM, Schakenraad JM, Horn JR. Cytotoxic, allergic and genotoxic activity of a nickel-titanium alloy. Biomaterials 1997; 18: 1115-20

[8] Wever DJ, Veldhuizen AG, Vries J, Busscher HJ, Uges DRA, Horn JR. Electrochemical and surface characterization of a nickeltitanium alloy. Biomaterials 1998; 19: 761-9.

[9] Filip P, Lausmaa J, Musialek J, Mazanec K. Structure and surface of TiNi human implants. Biomaterials 2001; 22: 2131-8.

[10] Flamini DO, Saidman SB. Electrodeposition of polypyrrole onto $\mathrm{NiTi}$ and the corrosion Behavior of the coated alloy. Corr Sci 2010; 52: 229-34.

[11] O'Brien B, Carroll WM, Kelly MJ. Passivation of nitinol wire for vascular implants - $\mathrm{a}$ demonstration of the benefits. Biomaterials 2002; 23: 1739-48.

[12] Michiardi A, Aparicio C, Planell JA, Gil FJ. Electrochemical behaviour of oxidized NiTi shape memory alloys for biomedical applications. Surf Coat Tech 2007; 201: 6484-8.

[13] Yan X, Yang D, Liu X. Electrochemical behavior of YAG laserwelded NiTi shape memory alloy. Transf Nonferrous Met Soc China 2006; 16: 572-6. 
[14] Villermaux F, Tabrizian M, Yahia LH, Meunier M, Piron DL. Excimer laser treatment of NiTi shape memory Alloy Biomaterials. App Surf Sci 1997; 109-110: 62-6.

[15] Tan L, Dodd RA, Crone WC. Corrosion and wear-corrosion behavior of NiTi modified by plasma source ion implantation. Biomaterials 2003; 24: 3931-9.

[16] Tuken T, Yazici B, Erbil M. The corrosion behaviour of polypyrrole coating synthesized in phenylphosphonic acid solution. App Surf Sci 2006; 252: 2311-8.

[17] Biallozor S, A Kupniewska Conducting polymers electrodeposited on active metals. Synthetic Metals 2005; 155: 443-9.

[18] Breslin CB, Fenelon AM, Conroy KG.. Corrosion protection using conducting polymers materials and design. Surf Eng 2005; 26: 2337.

[19] Martins NCT, Silva TM, Montemor MF, Fernandes JCS, Ferreira MGS. Electrodeposition and characterization of polypyrrole films on aluminium alloy 6061-T6. Electrochimica Acta 2008; 53: 475463.

[20] Arenas MA, Bajos LG, de Damborenea J J, Ocon P. Synthesis and electrochemical evaluation of polypyrrole coatings electrodeposited onto AA-2024 alloy. Prog Org Coat 2008; 62: 79-86.

[21] Li S, Qiu YB, Guo XP. Influence of doping anions on the ion exchange behavior of polypyrrole. J App Poly Sci 2009; 114: 230714

[22] Zhang T, Zeng CL. Corrosion protection of $1 \mathrm{Cr} 18 \mathrm{Ni9Ti}$ stainless steel by polypyrrole coatings in $\mathrm{HCl}$ aqueous solution. Electrochimica Acta 2005; 50: 4721-7.
[23] Sabouri M, Shahrabi T, Faridi HR, Hosseini MG. Polypyrrole and polypyrrole-tungstate electropolymerization coatings on carbon steel and evaluating their corrosion protection performance via electrochemical impedance spectroscopy. Prog Org Coat 2009; 64: 429-34.

[24] Grgur BN, Zivkovic P, Gvozdenovic MM. Kinetics of the mild steel corrosion protection by polypyrrole-oxalate coating in sulfuric acid solution. Prog Org Coat 2006; 56: 240-7.

[25] Hien NTL, Garcia B, Pailleret A, Deslouis C. Role of doping ions in the corrosion protection of iron by polypyrrole films. Electrochimica Acta 2005; 50: 1747-55.

[26] Tuken T, Arslan G, Yazıc1 B, Erbil M. The corrosion protection of mild steel by polypyrrole/polyphenol multilayer coating. Corr Sci 2004; 46: 2743-54.

[27] Hosseini MG, Sabouri M, Shahrabi T. Corrosion protection of mild steel by polypyrrole phosphate composite coating. Prog Org Coat 2007; 60: 178-85.

[28] Bereket G, Hur E. The corrosion protection of mild steel by single layered polypyrrole and multilayered polypyrrole/poly (5-amino-1naphthol) coatings. Progn Org Coatings 2009; 65: 116-24.

[29] B N Grgur, N V Krstajic, M V Vojnovic, C Lacnjevac, Lj GajicKrstajic. The influence of polypyrrole flms on the corrosion behavior of iron in acid sulfate solutions. Prog Org Coat 1998; 33 : $1-6$.

[30] Ren YJ, Zeng CL. Effect of conducting composite polypyrrole/ polyaniline coatings on the corrosion resistance of type 304 stainless steel for bipolar plates of proton-exchange membrane fuel cells. J Power Sources 2008; 182: 524-30.

(C) Qi et al.; Licensee Bentham Open.

This is an open access article licensed under the terms of the Creative Commons Attribution Non-Commercial License (http://creativecommons.org/licenses/by-nc/ 3.0/) which permits unrestricted, non-commercial use, distribution and reproduction in any medium, provided the work is properly cited. 